\title{
Delirium and Inflammation in Older Adults Hospitalized for COVID-19: A Cohort Study
}

\author{
Marie-France Forget (D) \\ Sophie Del Degan' \\ Julie Leblanc \\ Rita Tannous' \\ Michaël Desjardins ${ }^{2}$ \\ Madeleine Durand ${ }^{3,4}$ \\ Thien Tuong Minh $\mathrm{Vu}^{1,5}$ \\ Quoc Dinh Nguyen ${ }^{1,4}$ \\ Philippe Desmarais ${ }^{1,5}$ \\ 'Department of Medicine, Division of \\ Geriatrics, Centre Hospitalier de \\ I'Université de Montréal, Montréal, \\ Québec, Canada; ${ }^{2}$ Department of \\ Medicine, Division of Infectious Disease, \\ Centre Hospitalier de l'Université de \\ Montréal, Montréal, Québec, Canada; \\ ${ }^{3}$ Department of Medicine, Division of \\ Internal Medicine, Centre Hospitalier de \\ l'Université de Montréal, Montréal, \\ Québec, Canada; ${ }^{4}$ Innovation Hub, \\ Centre de Recherche du Centre \\ Hospitalier de l'Université de Montréal, \\ Montréal, Québec, Canada; ${ }^{5}$ Department \\ of Neurosciences, Centre de Recherche \\ du Centre Hospitalier de l'Université de \\ Montréal, Montréal, Québec, Canada
}

Correspondence: Marie-France Forget Department of Medicine, Division of Geriatrics, Centre Hospitalier de I'Université de Montréal, 1000 Rue SaintDenis, Montréeal, Québec, $\mathrm{H} 2 \times 0 \mathrm{Cl}$, Canada

Tel + I $5 \mid 48908000$

$\mathrm{Fax}+|-5| 4-4 \mid 2-7953$

Email marie-france.forget@umontreal.ca
Purpose: The occurrence and predictors of delirium in older adults hospitalized for coronavirus disease 2019 (COVID-19) have not been well described. Highlighting the association with inflammatory markers may be useful for identifying delirium. This study aimed to determine the prevalence and incidence of delirium and explore its association with the C-reactive protein (CRP).

Patients and Methods: This cohort study of adults aged 65 and older with a COVID-19 diagnosis took place at an academic healthcare institution between April and May 2020. COVID-19 was diagnosed by positive nasopharyngeal swab. Serum levels of CRP were collected as a marker of systemic inflammation. The primary outcome was the prevalence and incidence of delirium. Delirium was diagnosed primarily during a patient's stay in hospital based on the Diagnostic and Statistical Manual of Mental Disorders Fifth Edition (DSM-5). To ensure that no delirium diagnosis was missed during hospital stay, clinical records were reviewed by clinicians with geriatric medicine training for retrospective diagnoses.

Results: A total of 127 patients aged 65 and older were hospitalized with a diagnosis of COVID-19. The median age was 82 years (IQR: 74-88), with 54 (43\%) females. Overall, delirium was present in $62(49 \%)$ patients: manifestations of delirium were present on the first day of hospitalization in 53 of these cases $(86 \%)$, while 9 cases $(14 \%)$ developed delirium during hospitalization. After controlling for age and sex, the mean CRP value over the first 3 days since arrival was associated with a higher risk of delirium (OR 1.35; 95\% CI: $1.01-1.85$ ) for every $50 \mathrm{mg} / \mathrm{L}$ increase.

Conclusion: In this cohort of older adults hospitalized for COVID-19, delirium was highly prevalent. An early increase in CRP levels should raise suspicion about the occurrence of delirium and could improve its diagnosis.

Keywords: delirium, COVID-19, SARS-CoV-2, older adults

\section{Introduction}

Coronavirus disease 2019 (COVID-19), caused by the severe acute respiratory syndrome coronavirus 2 (SARS-CoV-2), is now recognized as a multisystemic disease. The most commonly reported manifestations of COVID-19 pertain to the respiratory, gastrointestinal, and vascular system. ${ }^{1-3}$ Neurologic manifestations, such as stroke, anosmia, and ageusia, are also an important proportion of the clinical presentations of COVID-19. ${ }^{1-3}$

Delirium, another neurological manifestation, has been reported in recent COVID-19 studies. ${ }^{1,4-8}$ Delirium diagnosis is based on a sudden or rapid alertness impairment, change in cognitive capacities, and fluctuation over time. ${ }^{9}$ Delirium is a well-known geriatric syndrome and a frequent atypical manifestation of common 
diseases in older adults. ${ }^{10}$ Delirium in hospitalized older adults is associated with worse outcomes, such as prolonged length of stay, worsening of disability, and increased in-hospital mortality. ${ }^{11,12}$ Delirium is often underreported, with varying prevalence ranging between $4 \%$ and $54 \%$ in hospitalized populations. ${ }^{12,13}$ Appropriately diagnosed delirium results in optimal treatment and lower risks of unfavorable outcomes. ${ }^{14}$

The literature on the epidemiology and characteristics of delirium in the context of COVID-19 in older adults is emerging. Little is known about the recognition of delirium in hospitalized patients, where its identification and management may be critical to improve COVID-19 care. Inflammatory response and coagulation activation have been found to explain part of COVID-19 manifestations. ${ }^{15}$ Highlighting the association between inflammatory markers and the occurrence of delirium may have clinical implications, as an easily available marker might enhance and structure care in response to delirium.

In this study, we described delirium prevalence at the time of hospital admission and incidence during hospitalization in a cohort of older adults with COVID-19. We also explored the association between C-reactive protein (CRP) serum levels and delirium.

\section{Patients and Methods Study Design}

We conducted a retrospective cohort study at the Centre hospitalier de l'Université de Montréal (CHUM), an academic healthcare institution designated as a reference treatment center for the province of Quebec, Canada. Briefly, during the first wave of the pandemic in Spring 2020, patients with COVID-19 requiring acute medical care were admitted on COVID-19 units from the emergency room or as transferred patients from regional community hospitals, rehabilitation centers, and long-term care facilities. COVID-19 units were managed by internists, with co-management of older patients with a unitdedicated geriatrician. The study was approved by the local research ethics committee (ie, Centre de Recherche du Centre hospitalier de l'Université de Montréal [CRCHUM]). As this was a retrospective study, patient consent to review their medical records was not required by IRB. Patient data were de-identified to ensure confidentiality of personal information, all in accordance with the Declaration of Helsinki.

\section{Data Collection}

\section{Participants}

We identified participants using electronic medical records and archives. We retrieved all consecutive admissions to COVID-19 units of patients aged 65 and older between April 20 and May 17, 2020. We included participants if a confirmed COVID-19 diagnosis was made (prior to or during the hospitalization) by a reverse-transcriptase polymerase chain reaction test from an oropharyngeal or nasal swab for SARS-CoV-2. Patients admitted to the psychiatric COVID-19 unit were excluded as their hospital admission was mainly required for their decompensated psychiatric condition and not for COVID-19 manifestations.

\section{Variables and Measures}

We collected patients' characteristics, eg, age, sex, comorbidities, functional status, place of residence, and clinical data, eg, vital signs, symptoms, and symptoms severity. We collected the serum CRP levels as a marker of inflammation. Our laboratories analyzed and reported serum specimens in $\mathrm{mg} / \mathrm{L}$, with the lowest possible reported value being $<5 \mathrm{mg} / \mathrm{L}$. Measured serum CRP levels following hospital admission were extracted from patients' medical records. Since CRP value for the first day following admission was frequently missing, the CRP 3-day mean value since admission for each patient was used as a marker of inflammation at baseline. We determined COVID-19 symptom severity using the 2007 Infectious Diseases Society of America/American Thoracic Society Criteria for Defining Severe Community-acquired Pneumonia. ${ }^{16}$ We quantified the comorbidities burden with the Charlson Comorbidity Index $(\mathrm{CCI})^{17}$ and measured functional status before admission using the Katz Index. ${ }^{18}$ Data collection was performed through chart review. Paired authors, all trained in geriatric medicine, working independently, extracted the data. Conflicts were resolved by consensus.

\section{Outcomes}

The primary outcome was the prevalence and incidence of delirium in older hospitalized adults with COVID-19. We defined prevalent delirium as a diagnosis of delirium made before or within 48 hours of admission, and incident delirium as a diagnosis of delirium made after 48 hours of admission. Internists and geriatricians diagnosed delirium based on the Diagnostic and Statistical Manual of Mental Disorders Fifth Edition (DSM-5) criteria. ${ }^{9}$ To ensure that no delirium diagnosis was missed during 
hospital stay, we also identified delirium diagnoses when these criteria were met through reported observations in the medical or nursing charts of hospitalized patients using a previously validated method. ${ }^{19}$ The retrospective delirium diagnosis was given by clinicians trained in geriatric medicine. Delirium was categorized into three psychomotor subtypes: hyperactive, hypoactive, and mixed. ${ }^{9}$

\section{Statistical Analysis}

We reported descriptive statistics with medians and interquartile ranges (IQR) for continuous variables and proportions for categorical variables. We used independent-samples Mann-Whitney test to compare continuous variables and Chi-squared tests for categorical variables. We reported delirium prevalence at the time of admission and incidence during hospitalization. We explored the association between delirium and length of stay (LOS) using linear regression adjusted for age and sex. We performed secondary analyses using logistic regression to examine the association between CRP serum levels and delirium, adjusted for age and sex. We computed the mean CRP value over the first 3 days since arrival as a predictor in the regression model (and used available case analysis). We excluded patients from these analyses with missing values regarding the CRP variable. Analyses were performed with SPSS Statistics (version 26) and R 4.0.0 (R Foundation for Statistical Computing).

\section{Results}

\section{Characterization of Study Sample}

A total of 127 patients aged 65 and older were admitted with a diagnosis of COVID-19 between April 20 and May 17, 2020. A summary of the demographic and clinical characteristics is provided in Table 1 . The median age was 82 years (IQR: 74-88), with 54 (43\%) females. Premorbid functional impairment in activities of daily living was frequent (60\%). Neurocognitive disorders and a history of a previous episode of delirium were prevalent, with, respectively, $52(41 \%)$ and $16(13 \%)$ cases.

\section{COVID-19 Presentation}

Initial presentations of COVID-19 were most frequently nonneurological for $106(83 \%)$ patients, with a respiratory illness presentation in $51(48 \%)$ patients and a classic viral syndrome presentation (fever, myalgia and headaches) in 13 (12\%) patients. COVID-19 symptoms were predominantly neurological for $14(11 \%)$ patients and were characterized by delirium, confusion, or impaired consciousness for 13 (93\%).
Table I Baseline Characteristics of Older Adults Hospitalized with COVID-19

\begin{tabular}{|c|c|}
\hline & $\begin{array}{l}\text { Total Cohort } \\
(n=\mid 27)\end{array}$ \\
\hline Age, median (IQR) & $82(74-88)$ \\
\hline Female (n, \%) & $54(43)$ \\
\hline \multicolumn{2}{|l|}{ Race (n, \%) } \\
\hline $\begin{array}{l}\text { White } \\
\text { Asian } \\
\text { Black }\end{array}$ & $\begin{array}{l}112(88) \\
9(7) \\
6(5)\end{array}$ \\
\hline \multicolumn{2}{|l|}{ Civil status (n, \%) } \\
\hline $\begin{array}{l}\text { Married } \\
\text { Widowed } \\
\text { Single } \\
\text { Divorced or separated } \\
\text { Unknown }\end{array}$ & $\begin{array}{l}39(3 \mathrm{I}) \\
28(22) \\
15(12) \\
9(7) \\
36(28)\end{array}$ \\
\hline \multicolumn{2}{|l|}{ Living location (n, \%) } \\
\hline $\begin{array}{l}\text { Private housing } \\
\text { Seniors' housing } \\
\text { Long-term care facility } \\
\text { Assisted living residence }\end{array}$ & $\begin{array}{l}42(33) \\
33(26) \\
31(24) \\
21(16)\end{array}$ \\
\hline \multicolumn{2}{|l|}{ Chronic conditions (n, \%) } \\
\hline $\begin{array}{l}\text { Visual impairment } \\
\text { Hearing impairment } \\
\text { Neurocognitive disorder } \\
\text { Alzheimer's disease } \\
\text { Vascular dementia } \\
\text { Mixed (vascular and Alzheimer) } \\
\text { Lewy body dementia/Parkinson's disease } \\
\text { dementia } \\
\text { Other } \\
\text { History of a previous delirium } \\
\text { Coronary heart disease } \\
\text { Heart failure } \\
\text { Vascular artery disease } \\
\text { Stroke or transient ischemic attack } \\
\text { Arterial hypertension } \\
\text { Diabetes } \\
\text { Lung disease } \\
\text { Kidney disease } \\
\text { Charlson Comorbidities Index score, } \\
\text { median (IQR) }\end{array}$ & $\begin{array}{l}66(52) \\
19(15) \\
52(41) \\
23(44) \\
8(15) \\
12(23) \\
1(2) \\
8(15) \\
16(13) \\
42(33) \\
21(17) \\
13(10) \\
20(16) \\
95(75) \\
43(34) \\
20(16) \\
26(20) \\
6(4-7)\end{array}$ \\
\hline \multicolumn{2}{|l|}{ Home medications $^{\mathrm{d}}(\mathrm{n}, \%)$} \\
\hline $\begin{array}{l}\text { Antipsychotic } \\
\text { Antidepressant } \\
\text { Anxiolytic } \\
\text { Opioid }\end{array}$ & $\begin{array}{l}33(26) \\
43(34) \\
27(21) \\
12(9)\end{array}$ \\
\hline
\end{tabular}

(Continued) 
Table I (Continued).

\begin{tabular}{|l|l|}
\hline & $\begin{array}{l}\text { Total Cohort } \\
(\mathbf{n}=\mathbf{1 2 7})\end{array}$ \\
\hline Anticonvulsant & $26(20)$ \\
Antiparkinsonian drug & $5(4)$ \\
Acetylcholinesterase inhibitor & $16(13)$ \\
Memantine & $3(2)$ \\
Preadmission functional impairment $^{\mathrm{e}}(\mathrm{n}, \%)$ & $76(60)$ \\
\hline
\end{tabular}

Notes: ${ }^{a}$ Vascular cerebral accident and ischemic transient attack excluded; b Including chronic obstructive pulmonary disease and asthma; ${ }^{c}$ Renal clearance of $30 \mathrm{~mL} /$ minute and less, hemodialysis, creatinine over $270 \mathrm{mmol} / \mathrm{mL}$, or post kidney transplant; 'Medication data from the patient's medication list at the time of admission; 'Measured using the Katz index. A score of 4 or less, indicating moderate to severe impairment.

Seventeen patients (13\%) had a severe pulmonary presentation at admission. Table 2 describes COVID-19 clinical presentations and the distribution of delirium risk factors. Bacterial pulmonary superinfection was reported in 37 patients (29\%) while another concomitant bacterial infection was reported in 20 patients (16\%). Thirty-nine patients (31\%) had an electrolyte imbalance.

\section{Delirium Prevalence, Incidence and Characteristics}

Table 3 describes delirium characteristics and diagnosis. Delirium was identified in $62(49 \%)$ patients. Manifestations of delirium were present on the first day of hospitalization for $53(86 \%)$ of these cases. Nine (14\%) cases developed during hospitalization. Delirium was diagnosed explicitly in 46 (74\%) cases; 16 (26\%) diagnoses were based on criteria following examination of the medical or nursing progress notes. Of the latter, 24 (39\%) referred to delirium symptoms before admission. Delirium, as a predominant or concomitant clinical manifestation of COVID-19, was present for $53(42 \%)$ patients on the first day of hospitalization. Delirium onset was reported with a median of 5 days (2-8) after the first symptom of COVID-19. Delirium psychomotor subtype was hypoactive for 23 (37\%) and mixed for 29 (47\%). Patients who developed delirium did not differ significantly from those who did not with regard to age, sex, living location, comorbidities (including neurocognitive disorder), and medication. Premorbid functional impairment was more common in the delirium group ( $69 \%$ vs $51 \%, p=0.026)$. A summary of the characteristics and initial presentation of COVID-19 in the delirium and non-delirium groups is provided in Table S1 and S2.
Table 2 Initial Clinical Presentation of COVID-19 and Risk Factors for Delirium

\begin{tabular}{|c|c|}
\hline & $\begin{array}{l}\text { Total Cohort } \\
\qquad(n=127)\end{array}$ \\
\hline \multicolumn{2}{|l|}{ Main initial manifestation reported $(\mathrm{n}, \%)$} \\
\hline Non-neurological & $106(83)$ \\
\hline Respiratory & $51(48)$ \\
\hline Gastrointestinal & $12(11)$ \\
\hline Vascular & $3(3)$ \\
\hline $\begin{array}{l}\text { Classic viral syndrome (fever, myalgia, } \\
\text { headaches) }\end{array}$ & $13(12)$ \\
\hline Multidimensional presentation ${ }^{\text {a }}$ & $27(25)$ \\
\hline Neurological & $14(11)$ \\
\hline Altered mental status ${ }^{b}$ & $13(93)$ \\
\hline Motor deficit & I (7) \\
\hline Asymptomatic & $7(6)$ \\
\hline Severe presentation ${ }^{c}(n, \%)$ & $17(13)$ \\
\hline \multicolumn{2}{|c|}{ Medical conditions and risk factors for delirium $(n, \%)$} \\
\hline Bacterial superinfection & $57(45)$ \\
\hline Bacterial pulmonary infection & $37(65)$ \\
\hline Other bacterial infection & $20(35)$ \\
\hline $\begin{array}{l}\text { Vascular cerebral accident and ischemic } \\
\text { transient attack }\end{array}$ & $6(5)$ \\
\hline Acute renal failure & $6(5)$ \\
\hline Electrolyte imbalance & $39(31)$ \\
\hline
\end{tabular}

Notes: ${ }^{a}$ Various noticeable symptoms and signs without specific predominance; bDelirium, confusion, impaired consciousness; 'Symptoms severity according to the 2007 Infectious Diseases Society of America/American Thoracic Society Criteria for Defining Severe Community-acquired Pneumonia.

\section{Hospitalization Outcomes According to Presence/Absence of Delirium}

Table 4 describes hospitalization outcomes according to presence of delirium. Delirium was reported in 9 of 15 $(60 \%)$ patients admitted to the intensive care unit. There were $36(58 \%)$ deaths in patients with delirium, compared to $17(26 \%)$ in those without. After adjustment for sex and age, death was more frequent in the delirium group (OR 4.00; $95 \%$ CI: $1.83-8.73, \mathrm{p}=0.001$ ), and the length of stay was greater in survivors who developed delirium (differences in LOS of 9.26; 95\% CI: 3.75-14.76, p = 0.001).

\section{Association Between CRP Levels, Delirium and Death}

In the entire cohort, CRP levels ranged from 5 to $324 \mathrm{mg} / \mathrm{L}$ (median 87 [44-146]). CRP median value was higher in those who developed delirium than those who did not (109 [61-161] vs 68 [40-117], $\mathrm{p}=0.017)$. 
Table 3 Delirium Characteristics and Diagnosis

\begin{tabular}{|c|c|}
\hline & $\begin{array}{l}\text { Delirium } \\
(n=62)\end{array}$ \\
\hline \multicolumn{2}{|l|}{ Delirium diagnosis (n, \%) } \\
\hline Reported delirium diagnosis & $46(74)$ \\
\hline $\begin{array}{l}\text { Retrospectively identified delirium case based on medical } \\
\text { chart abstraction }\end{array}$ & $16(26)$ \\
\hline \multicolumn{2}{|l|}{ Onset of delirium $(n, \%)$} \\
\hline Delirium reported before admission & $24(39)$ \\
\hline $\begin{array}{l}\text { Delirium described in the COVID-19 presentation on } \\
\text { the day of admission without previous reported signs }\end{array}$ & $29(47)$ \\
\hline Delirium reported after admission & $9(14)$ \\
\hline \multicolumn{2}{|l|}{ Delirium psychomotor subtype $(n, \%)$} \\
\hline Hypoactive & $23(37)$ \\
\hline Hyperactive & $10(16)$ \\
\hline Mixed & $29(47)$ \\
\hline $\begin{array}{l}\text { Interval in days between first COVID-19 symptom and } \\
\text { delirium, median (IQR) }\end{array}$ & $5(2-8)$ \\
\hline Delirium length, in days (median, IQR) & $8(4-15)$ \\
\hline
\end{tabular}

Table 5 presents the results of the multivariable analysis for the association between CRP levels and the presence of delirium. After adjustment for sex and age, a greater mean CRP value over the first 3 days since arrival was associated with a higher risk of delirium (OR 1.35; 95\% CI: $1.01-1.85 ; \mathrm{p}=0.049$, for every $50 \mathrm{mg} / \mathrm{L}$ increase). After adjusting for the same variables, a greater mean CRP value over the first 3 days since arrival was also independently associated with death (OR 1.68; 95\% CI: $1.23-2.40 ; \mathrm{p}=0.002$ ).

\section{Discussion}

Delirium was highly prevalent and was a frequent early manifestation of disease in our cohort of older adults hospitalized for COVID-19. Delirium was the main initial clinical presentation of COVID-19 in 10\% of COVID-19 cases. Overall, $49 \%$ of patients developed delirium during the course of their disease. Increased CRP values in the 3 first days of hospital admission were associated with an increased risk of delirium.

Presenting symptoms of common diseases in older adults are known to be often atypical; delirium, fall and functional decline are examples of frequent atypical manifestations. ${ }^{10,20}$ In our cohort, respiratory symptoms remain the most prevalent initial presentation of COVID-19, as reported in previous studies. $^{21-24}$ Our current findings concerning delirium and other neurological presentations are in line with the atypical presentation of COVID-19 in older adults. In a cohort of adults aged 70 years and older, admitted to hospital with COVID-19, fall, reduced mobility, and delirium were presenting symptoms for $28 \%, 45 \%$, and $29 \%$, respectively. ${ }^{21}$ Similarly in other COVID-19 population studies, delirium prevalence at onset was between $11 \%$ and $25 \%$ in an acute care geriatric ward, ${ }^{24}$ ${ }^{27} 12 \%$ in a younger cohort of 50 years and older, ${ }^{6} 36.8 \%$ in an older adult cohort with dementia, ${ }^{28}$ and $67 \%$ in an older cohort with dementia having a mostly atypical presentation. ${ }^{29}$ In a recent systematic review, which included 3,868 older adults, delirium prevalence was $27 \%{ }^{30}$ The high rate of delirium diagnosed at admission in our cohort may be explained by the performance of a comprehensive geriatric assessment of admitted older patients, which includes determining the cognitive pre-admission status, thus facilitating the identification of delirium. Repeated delirium assessments increase the identification of delirium. ${ }^{31}$ Moreover, our delirium identification method included direct diagnosis and retrospective diagnosis based on medical or nursing observations. As was found by Vrillon et al, the high mean age of our cohort may explain the high prevalence of delirium. ${ }^{32}$ Similar to other COVID-19 cohort studies of adults aged above 50 and 65 years, ${ }^{6,8}$

Table 4 Hospitalization Outcomes According to Presence of Delirium

\begin{tabular}{|c|c|c|c|c|}
\hline Variables & Occurrence & Adjusted Estimates ${ }^{\text {a }}$ & $95 \% \mathrm{Cl}$ & p-value \\
\hline Death $(\mathrm{n}, \%)$ & $53(42)$ & 4.00 & $1.83-8.73$ & 0.001 \\
\hline Length of hospital stay, in days, median (IQR), $\mathrm{n}=127$ & $14(7-24)$ & 2.26 & $-2.05-6.51$ & 0.305 \\
\hline Length of hospital stay, in days, median (IQR) excluding deaths, $n=74$ & $19(12-27)$ & 9.26 & $3.75-14.76$ & 0.001 \\
\hline Length of hospital stay before death, in days, median (IQR), $n=53$ & $7(4-12)$ & 0.53 & $-5.29-6.36$ & 0.854 \\
\hline Intensive care unit admission ( $\mathrm{n}, \%)$ & $15(12)$ & 2.76 & $0.80-9.57$ & 0.110 \\
\hline Length of stay in intensive care unit in days, median (IQR) & II (8-33) & 2.47 & $-12.79-17.7$ & 0.729 \\
\hline
\end{tabular}

Notes: ${ }^{a}$ Estimates are presented as odds ratios for dichotomous outcomes and as differences for lengths of stay. All multivariable analyses were adjusted for age and sex. 
Table 5 Associations of C-Reactive Protein Serum Levels with Delirium and Mortality ${ }^{\mathrm{a}}$

\begin{tabular}{|c|c|c|c|}
\hline Delirium & $\mathbf{O R}^{\mathbf{b}}$ & $95 \% \mathrm{Cl}$ & p-value \\
\hline C-reactive protein (CRP) 3-day mean value since admission (per $50 \mathrm{mg} / \mathrm{L}$ increase) & 1.35 & $1.01-1.85$ & 0.049 \\
\hline Male sex & 0.66 & $0.28-1.52$ & 0.332 \\
\hline Age (per 10 year increase) & 1.34 & $0.82-2.16$ & 0.268 \\
\hline Mortality & $O R^{b}$ & $95 \% \mathrm{Cl}$ & P-value \\
\hline CRP 3-day mean value since admission (per $50 \mathrm{mg} / \mathrm{L}$ increase) & 1.68 & $1.23-2.40$ & 0.002 \\
\hline Male sex & 1.11 & $0.45-2.74$ & 0.818 \\
\hline Age (per 10 year increase) & 1.64 & I.10-2.84 & 0.046 \\
\hline
\end{tabular}

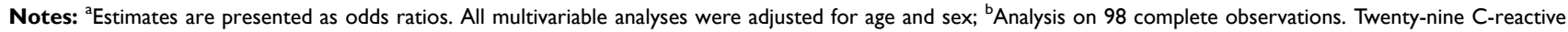
protein missing values.

delirium in our study was associated with adverse outcomes, such as increased mortality ${ }^{26}$ and prolonged length of stay. Moreover, a hospitalized COVID-19 cohort study highlighted that neurologic symptoms, such as dizziness, headaches and impaired consciousness, were associated with more severe infection. ${ }^{1}$

Our results support the evidence of an association between inflammation and delirium, similar to findings of studies in the perioperative setting, ${ }^{33-35}$ and in the context of trauma and sepsis. ${ }^{36}$ More severe signs and symptoms of COVID-19 have been associated with a CRP higher than $41.8 \mathrm{mg} / \mathrm{L}$ in a recent retrospective cohort. ${ }^{37}$ In the pre-cited systematic review, which included 3,868 older adults, every $1 \mathrm{mg} / \mathrm{L}$ increase in CRP was associated with $1 \%$ increased delirium risk (OR 1.01 [1.00. 1.02], $\mathrm{p}=0.033$ ). However, the CRP measurement moment was not specified. ${ }^{30}$

These findings suggest that CRP levels in COVID-19 may have clinical utility as a predictor of delirium, as well as death, in older adults hospitalized. The magnitude of the association is small and is based on a $50 \mathrm{mg} / \mathrm{L}$ CRP raise. It is still of clinical and theoretical interests. A sensitive and specific cut-off value that is clinically relevant remains to be determined and we will have to consider age-related changes in immunity, which include higher inflammatory marker levels during infections with aging. ${ }^{22,38}$

Delirium recognition during admission and during hospitalization is challenging, and the COVID-19 related isolation measures might further increase the challenge. Twenty-six percent of delirium cases were retrospectively identified based on medical charts but were not diagnosed or reported explicitly by treating physicians. This suggests important missed opportunities to screen, detect, and treat delirium and its underlying precipitating factors. Systematic screening of delirium in the initial medical assessment of older adults hospitalized for COVID-19 is required to improve its management. Furthermore, increased CRP serum levels in the first few days following admission could be used as a predictor of delirium. Recognition and deliberate identification of delirium are critical in older adults with COVID-19, whether as a presenting manifestation of the infection, in the course of the disease, or as a complication. ${ }^{39}$ Conversely, a diagnosis of delirium in an older adult in the context of a high community transmission rate of SARS-CoV-2 should warrant ruling out COVID-19.

Our study has several strengths. First, to our knowledge, this is the first study to assess the association between delirium and inflammation in a cohort of older adults with COVID-19. Second, we used a rigorous medical record and chart extraction approach using two independent reviewers; this has allowed us to identify undiagnosed or unreported cases of delirium, providing us with a better estimate of the true rate of delirium in older adults hospitalized for COVID-19. Third, we assessed for the occurrence of delirium throughout the course of the disease, whether before or at the time of admission or during hospitalization. Limitations should be highlighted. First, despite our robust extraction approach, we may have underestimated the true rate of delirium as other cases may have been missed due to undocumented symptoms and signs, especially in the case of hypoactive delirium. Second, we were not powered to further explore and characterize the association between systemic inflammation and delirium. The association found between CRP and delirium may not be causally related. Moreover, CRP 
values were missing for more than $20 \%$ of the cohort. Our exploratory results will have to be replicated by future studies. Nonetheless, increased CRP serum levels were found to be associated with delirium in our cohort. This association was revealed by exploratory analysis, without considering multiple potential covariates and confounding variables. It should be reassessed in future studies. Third, the identification of the main initial presentation of COVID-19 was challenging because of the retrospective nature of the study, relying on the completeness and accuracy of the medical charts. Finally, this study took place in a single academic centre during unprecedented times where models of providing medical care were drastically adapted. Hence, generalizability could be a concern.

\section{Conclusion}

In this cohort of older adults hospitalized for COVID-19, delirium was highly prevalent. Delirium was an initial predominant neurological manifestation of COVID-19 in $10 \%$ of our cohort and occurred in nearly $50 \%$ of patients during the course of their disease. When it occurred, delirium was present on the first day of hospitalization in $86 \%$ of cases. An early increase in CRP levels should raise suspicion about the occurrence of delirium. Early diagnosis and management of delirium in older adults hospitalized for COVID-19 might improve outcomes.

\section{Disclosure}

The authors report no conflicts of interest in this work.

\section{References}

1. Mao L, Jin H, Wang M, et al. Neurologic manifestations of hospitalized patients with coronavirus disease 2019 in Wuhan, China. JAMA Neurol. 2020;77(6):683. doi:10.1001/jamaneurol.2020.1127

2. Avula A, Nalleballe K, Narula N, et al. COVID-19 presenting as stroke. Brain Behav Immun. 2020;87:115-119. doi:10.1016/j. bbi.2020.04.077

3. Liu K, Pan M, Xiao Z, Xu X. Neurological manifestations of the coronavirus (SARS-CoV-2) pandemic 2019-2020. J Neurol Neurosurg Psychiatry. 2020;91(6):669-670. doi:10.1136/jnnp-2020323177

4. Helms J, Kremer S, Merdji H, et al. Neurologic features in severe SARS-CoV-2 infection. $N$ Engl J Med. 2020;382(23):2268-2270 doi:10.1056/NEJMc2008597

5. Almqvist J, Granberg T, Tzortzakakis A, et al. Neurological manifestations of coronavirus infections - a systematic review. Ann Clin Transl Neurol. 2020;7(10):2057-2071. doi:10.1002/acn3.51166

6. Garcez FB, Aliberti MJR, Poco PCE, et al. Delirium and adverse outcomes in hospitalized patients with COVID-19. J Am Geriatr Soc. 2020;68(11):2440-2446. doi:10.1111/jgs.16803

7. Zazzara MB, Penfold RS, Roberts AL, et al. Probable delirium is a presenting symptom of COVID-19 in frail, older adults: a cohort study of 322 hospitalised and 535 community-based older adults. Age Ageing. 2021;50:40-48
8. Kennedy M, Helfand BKI, Gou RY, et al. Delirium in older patients with COVID-19 presenting to the emergency department. JAMA Network Open. 2020;3(11):e2029540. doi:10.1001/jamanetworkopen.2020.29540

9. American Psychiatric Association. DSM-5, Diagnostic and Statistical Manual of Mental Disorders. 5th ed. Arlington, VA: American Psychiatric Association; 2013.

10. Peters ML. The older adult in the emergency department: aging and atypical illness presentation. J Emerg Nurs. 2010;36(1):29-34. doi:10.1016/j.jen.2009.06.014

11. Witlox J, Eurelings LS, de Jonghe JF, Kalisvaart KJ, Eikelenboom P, van Gool WA. Delirium in elderly patients and the risk of postdischarge mortality, institutionalization, and dementia: a meta-analysis. JAMA. 2010;304(4):443-451. doi:10.1001/ jama.2010.1013

12. Inouye SK, Westendorp RG, Saczynski JS. Delirium in elderly people. Lancet. 2014;383(9920):911-922. doi:10.1016/S01406736(13)60688-1

13. Gibb K, Seeley A, Quinn T, et al. The consistent burden in published estimates of delirium occurrence in medical inpatients over four decades: a systematic review and meta-analysis study. Age Ageing. 2020;49(3):352-360. doi:10.1093/ageing/afaa040

14. Lundstrom M, Edlund A, Karlsson S, Brannstrom B, Bucht G, Gustafson Y. A multifactorial intervention program reduces the duration of delirium, length of hospitalization, and mortality in delirious patients. J Am Geriatr Soc. 2005;53(4):622-628. doi:10.1111/j.15325415.2005.53210.x

15. Merad M, Martin JC. Pathological inflammation in patients with COVID-19: a key role for monocytes and macrophages. Nat Rev Immunol. 2020;20:355-362.

16. Mandell LA, Wunderink RG, Anzueto A, et al. Infectious diseases society of America/American thoracic society consensus guidelines on the management of community-acquired pneumonia in adults. Clin Infect Dis. 2007;44(Suppl 2):S27-S72.

17. Charlson ME, Pompei P, Ales KL, MacKenzie CR. A new method of classifying prognostic comorbidity in longitudinal studies: development and validation. $J$ Chronic Dis. 1987;40(5):373-383. doi:10.1016/0021-9681(87)90171-8

18. Katz S. Assessing self-maintenance: activities of daily living, mobility, and instrumental activities of daily living. $J$ Am Geriatr Soc. 1983;31(12):721-727. doi:10.1111/j.1532-5415.1983.tb03391.x

19. Kuhn E, Du X, McGrath K, et al. Validation of a consensus method for identifying delirium from hospital records. PLoS One. 2014;9 (11):e111823. doi:10.1371/journal.pone.0111823

20. Hofman MR, van den Hanenberg F, Sierevelt IN, Tulner CR. Elderly patients with an atypical presentation of illness in the emergency department. Neth J Med. 2017;75(6):241-246.

21. Knopp P, Miles A, Webb TE, et al. Presenting features of COVID-19 in older people: relationships with frailty, inflammation and mortality. Eur Geriatr Med. 2020;11(6):1089-1094. doi:10.1007/s41999-02000373-4

22. Liu K, Chen Y, Lin R, Han K. Clinical features of COVID-19 in elderly patients: a comparison with young and middle-aged patients. J Infect. 2020;80(6):e14-e18. doi:10.1016/j.jinf.2020.03.005

23. Wei C, Liu Y, Liu Y, et al. Clinical characteristics and manifestations in older patients with COVID-19. BMC Geriatr. 2020;20(1):395. doi:10.1186/s12877-020-01811-5

24. Gan JM, Kho J, Akhunbay-Fudge M, et al. Atypical presentation of COVID-19 in hospitalised older adults. Ir J Med Sci. 2021;190 (2):469-474. doi:10.1007/s11845-020-02372-7

25. Zerah L, Baudouin E, Pepin M, et al. Clinical characteristics and outcomes of 821 older patients with SARS-Cov-2 infection admitted to acute care geriatric wards. J Gerontol A Biol Sci Med Sci. 2020.

26. Mendes A, Herrmann FR, Perivier S, Gold G, Graf CE, Zekry D. Delirium in older patients with COVID-19: prevalence, risk factors and clinical relevance. J Gerontol a Biol Sci Med Sci. 2021. doi:10.1093/gerona/glab039 
27. Annweiler C, Sacco G, Salles N, et al. National French survey of coronavirus disease (COVID-19) symptoms in people aged 70 and over. Clin Infect Dis. 2021;72(3):490-494. doi:10.1093/cid/ciaa792

28. Poloni TE, Carlos AF, Cairati M, et al. Prevalence and prognostic value of Delirium as the initial presentation of COVID-19 in the elderly with dementia: an Italian retrospective study. EClinicalMedicine. 2020;26:100490. doi:10.1016/j.eclinm.2020.100490

29. Bianchetti A, Rozzini R, Guerini F, et al. Clinical presentation of COVID19 in dementia patients. $J$ Nutr Health Aging. 2020;24 (6):560-562. doi:10.1007/s12603-020-1389-1

30. Pranata R, Huang I, Lim MA, Yonas E, Vania R, Kuswardhani RAT. Delirium and mortality in coronavirus disease 2019 (COVID-19) a systematic review and meta-analysis. Arch Gerontol Geriatr. 2021;95:104388. doi:10.1016/j.archger.2021.104388

31. de Freitas SA, Wong E, Lee JY, et al. The effect of multiple assessments on delirium detection: a pilot study. Can Geriatr J. 2020;23 (4):277-282. doi: $10.5770 /$ cgj.23.433

32. Vrillon A, Hourregue C, Azuar J, et al. COVID-19 in older adults: a series of 76 patients aged 85 years and older with COVID-19. J Am Geriatr Soc. 2020;68(12):2735-2743. doi:10.1111/jgs. 16894

33. Dillon ST, Vasunilashorn SM, Ngo L, et al. Higher C-reactive protein levels predict postoperative delirium in older patients undergoing major elective surgery: a longitudinal nested case-control study. Biol Psychiatry. 2017;81(2):145-153. doi:10.1016/j.biopsych.2016.03.2098
34. Vasunilashorn SM, Dillon ST, Inouye SK, et al. High C-reactive protein predicts delirium incidence, duration, and feature severity after major noncardiac surgery. $J$ Am Geriatr Soc. 2017;65(8): e109-e116. doi:10.1111/jgs.14913

35. Khan BA, Perkins AJ, Prasad NK, et al. Biomarkers of delirium duration and delirium severity in the ICU. Crit Care Med. 2020;48 (3):353-361. doi:10.1097/CCM.0000000000004139

36. Wilson JE, Mart MF, Cunningham C, et al. Delirium. Nat Rev Dis Primers. 2020;6(1):1-26.

37. Liu F, Li L, Xu M, et al. Prognostic value of interleukin-6, C-reactive protein, and procalcitonin in patients with COVID-19. J Clin Virol. 2020;127:104370. doi:10.1016/j.jcv.2020.104370

38. Girard TD, Opal SM, Ely EW. Insights into severe sepsis in older patients: from epidemiology to evidence-based management. Clin Infect Dis. 2005;40(5):719-727. doi:10.1086/427876

39. LaHue SC, James TC, Newman JC, Esmaili AM, Ormseth CH, Ely EW. Collaborative delirium prevention in the age of COVID-19. J Am Geriatr Soc. 2020;68(5):947-949. doi:10.1111/ jgs. 16480
Clinical Interventions in Aging

\section{Publish your work in this journal}

Clinical Interventions in Aging is an international, peer-reviewed journal focusing on evidence-based reports on the value or lack thereof of treatments intended to prevent or delay the onset of maladaptive correlates of aging in human beings. This journal is indexed on PubMed Central, MedLine, CAS, Scopus and the Elsevier

\section{Dovepress}

Bibliographic databases. The manuscript management system is completely online and includes a very quick and fair peer-review system, which is all easy to use. Visit http://www.dovepress.com/ testimonials.php to read real quotes from published authors. 